\title{
Omega-3 polyunsaturated fatty acids and mood disorders
}

Pierre ASTORG

Unité Nutrition et Régulation Lipidique des Fonctions Cérébrales (Nu.Ré.Li.Ce), INRA, Centre de Jouy, bât. 230, Domaine de Vilvert, 78352 Jouy-en-Josas Cedex

$<$ pierre.astorg@jouy.inra.fr>

\begin{abstract}
The hypothesis of a role of $n-3$ polyunsaturated fatty acids (PUFA) in the pathophysiology of depression has emerged from the observation that depressed patients had decreased levels of $n-3$ long-chain PUFA (especially eicosapentaenoic acid, EPA, and docosahexaenoic acid, DHA) in plasma, erythrocytes, or adipose tissue, as compared to healthy controls, a decrease which was not observed with n-6 PUFA. Suicide attempters have much lower levels of EPA and DHA in red blood cells than hospital controls. Recently, a decreased level of DHA has also been observed in the post-mortem brain cortex of patients with major depression. The fact that these changes were specific of the $n-3$ family suggests that a low n-3 PUFA status or intake predisposes to depression. International ecological studies show a strong negative correlation between apparent fish consumption and the prevalence of depression or of bipolar disorder, as well as between DHA content of maternal milk and the prevalence of postpartum depression. In cross-sectional studies in several countries, a higher risk of depression or of depressive symptoms has been found in subjects with a lower fish consumption. In a French cohort of adults, habitual fatty fish consumption or a higher n-3 PUFA intake were associated with a lower risk of depression, especially of recurrent depression. Randomized, placebo-controlled trials have been conducted to test the effects of long-chain n-3 PUFA in depressive or bipolar patients. EPA as an adjunct to a standard treatment appears to improve depressive patients or bipolar patients in depressive phase when given at the dose of $1-2 \mathrm{~g} /$ day, and fish oil prevents depressive recurrences in bipolar patients. Recently, a mixture of EPA plus DHA has proven efficiency in untreated depressive children. In summary, many epidemiological and clinical works in the last ten years have abundantly documented the existence of an association between a low n-3 PUFA intake or status and a greater risk of mood disorder, as well as a therapeutic potential of $n-3$ PUFA in depressed or bipolar patients. Other works are necessary in order to establish a causal relation between n-3 PUFA deficiency and depression, and to further explore their preventive or therapeutic use.
\end{abstract}

Key words: depression, mood disorders, omega-3 fatty acids, EPA, DHA, fish

sion frequency is high in France, where a lifelong prevalence of about $20 \%$ has been found (12-15\% in men and $24-27 \%$ in women) [1]. Due to their high prevalence, depressive disorders have major socio-economic consequences. According to the WHO data, depression was the fourth cause of disability in the world in 2000, and is expected to become the second one in 2020 [2]. In addition, depression increases mortality rate, and not only suicide mortality [3], and increasing evidence suggests that it is an independent risk factor for major chronic diseases, especially for dementias [4]. Thus, in many countries and especially in France, depression is a major public health problem, and the research of prevention factors is a major public health issue.

In addition to known risk factors of depression such as familial history and stressful life events, great international differences in its prevalence suggest an important impact of sociocultural and/or environmental factors. Recent research have shown the possible influence of nutritional factors on depression, especially of $n-3$ polyunsaturated fatty acids (n-3 PUFA).

\section{Blood \& tissue n-3 PUFA and depression : observations in clinical settings}

A decrease of n-3 PUFA, especially of longchain n-3 PUFA, has often been observed in plasma or erythrocyte lipids of unipolar depressed patients relatively to nondepressed control subjects [5-9]. This decrease could involve either EPA [5] or DHA [7] or several n-3 PUFA, including a-linolenic acid [5-10], but were specific of n-3 PUFA: $n-6$ PUFA, such as linoleic acid, arachidonic acid or 22: $5 \mathrm{n}-6$, were not decreased. In contrast, manic bipolar patients had strongly decreased levels of both arachidonic and DHA in erythrocyte lipids. In a few studies, n-3 PUFA contents were negatively correlated with the intensity of depressive symptoms $[5,6]$ (figure 1), which suggests that the decrease of $n-3$ PUFA was directly linked to the depressive state. However, the levels of $n-3$ PUFA were not found to rise to control levels as the patients under antidepressant treatment improved with time [9]. Recently, a selective decrease of DHA has been observed post mortem in the orbifrontal cortex of patients with 


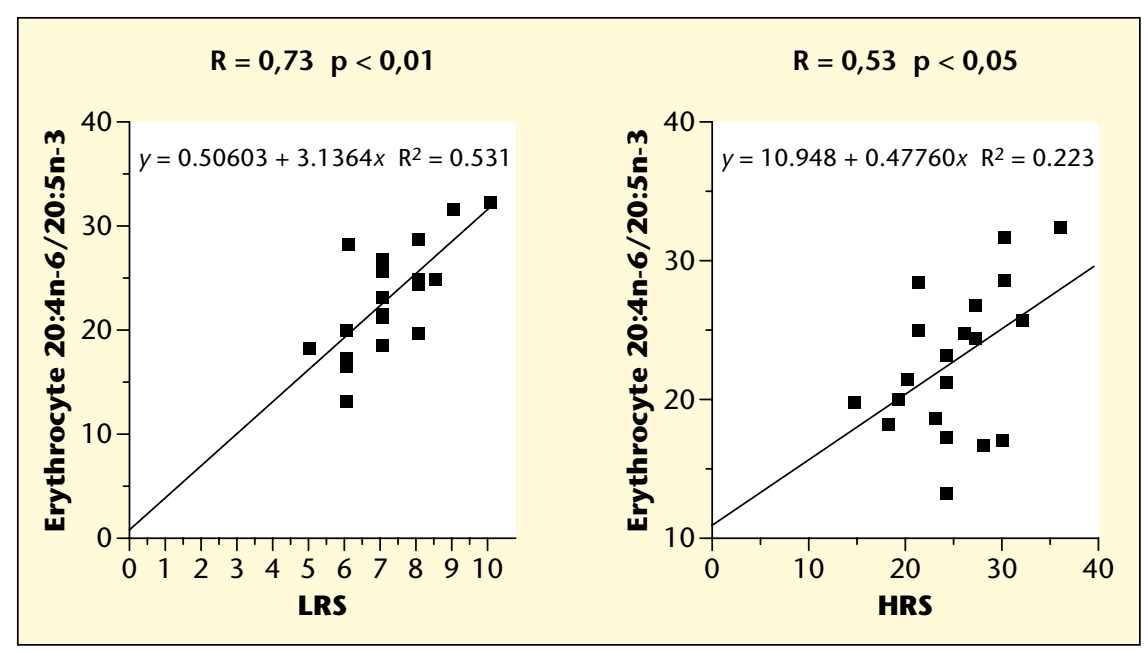

Figure 1. Arachidonic acid/EPA ratio in erythrocyte PL correlates positively with symptoms of depression (from Adams et al., [5]).

major depressive disorder [11] (figure 2). Depression is generally accompanied by an inflammatory state, with an increase of proinflammatory cytokines, generating an oxidative stress $[9,12,13]$, which causes an increase of markers of lipid peroxidation and a decrease of vitamin $E$ in blood, as well as the induction of antioxidant enzymes $[9,12,13]$, and thus could explain the decrease of n-3 PUFA in depression. However, it does not explain why the decrease of PUFA is selective of the $n-3$ family. Since the depressive state often causes a decreased appetite and a lower food intake, it could result in a decreased PUFA intake. Again, this hypothesis does not explain the fact that the PUFA decrease in depression is apparently limited to the $n-3$ family. An alternative hypothesis is that a pre-existing lower n-3 PUFA status, due in particular to a lower n-3 PUFA intake, could promote the onset of depression, as suggested by a study where both the blood levels and the dietary intakes of n-3 PUFA were inversely correlated to depressive symtoms [6]. Several studies in population settings have explored this hypothesis.

\section{Fish intake, n-3 PUFA and mood disorders: observational epidemiological studies}

Since fish is, worldwide, the main food source of long-chain n-3 PUFA, epidemiological studies have examined the relation between fish consumption and mood disorder rate. A crossnational correlation study has shown an inverse relation between apparent fish consumption calculated from economical FAO statistics and the prevalence of major depressive disorder,

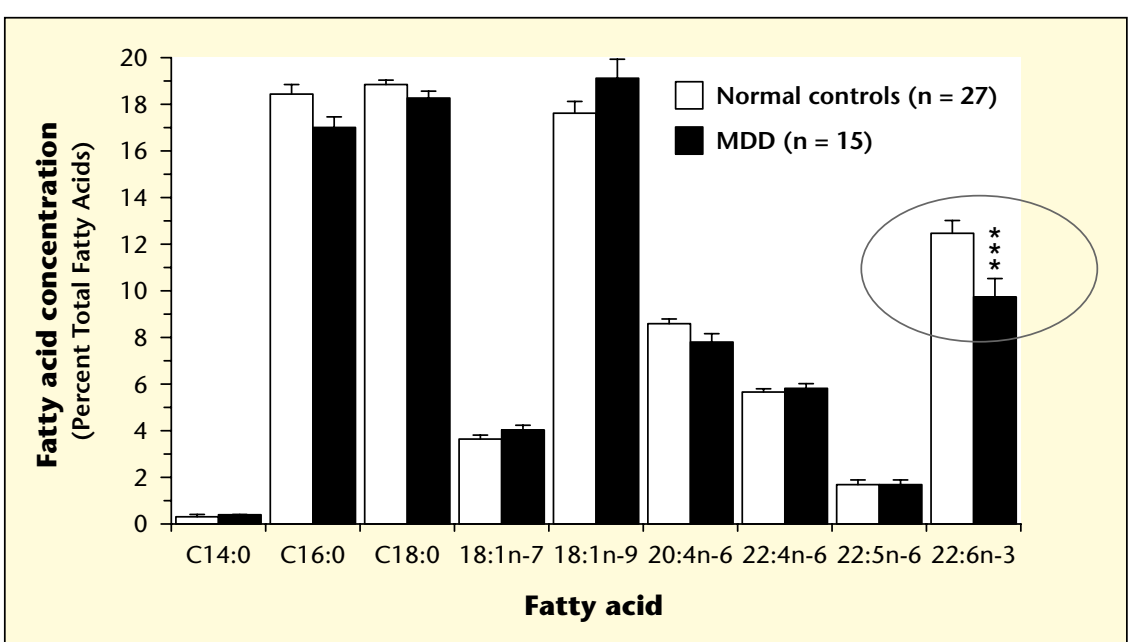

Figure 2. Selective deficit in DHA in the postmortem orbifrontal cortex of patients with major depressive disorder (from McNamara et al., [11]).

the Asian countries with a high fish consumption (Japan, Taiwan, Korea) having a low depression prevalence [14] (figure 3). The same cross-national relation has been found for postpartum depression, the frequency of which is lower in countries with higher intake of fish or with higher DHA content of maternal milk [15]. Again, Asian countries (Malaysia, Singapore, Hong Kong, and Japan), but also Chile, were countries with higher fish consumption and lower post-partum depression rates. The prevalence of bipolar spectrum disorders has been found decrease still more steeply with fish and seafood consumption [16] (figure 4). The inverse relation appears stronger for bipolar II than for bipolar I disorder. Interestingly, such a negative correlation is not observed between the rate of schizophrenia and fish consumption in the same countries, which suggests that the relation is specific of mood disorders [16]. This type of ecological study is not conclusive, since the differences can be due to many confounding factors, especially to genetic, economical or socio-cultural differences between countries. However, the fact that Iceland ranks, with Asian countries, among the countries with low rates of mood disorders is an argument in favor of the "fish hypothesis". The association of infrequent fish consumption with a greater risk of depression or depressive symptoms has been found in several cross-sectional studies in populations from Finland [17-19], France [20], or New Zealand [21]. In several of these studies, even a moderate fish consumption (once a week vs. less than once a week) was associated to a decreased risk of current depression/ depressive symptoms [18-21]. In one study, both current depressive symptoms and lifetime diagnoses of depression have been assessed [19]. Interestingly, fish consumption was associated with a decreased risk of current depression in women $(\mathrm{OR}=0.71[0.55-0.91])$, but more strongly with a decreased risk of both current and past depression (OR $=0.42[0.24$ 0.71]) [19]. In population samples, subjects with depression or depressive symptoms have been found to have lower plasma or adipose tissue levels of n-3 PUFA, especially of DHA, than non-depressed subjects $[22,23]$. The study using adipose tissue fatty acids as biomarkers [22] is suggestive of a causal effect of a low n-3 PUFA status on depression: since adipose tissue PUFAs have a very slow turnover (several years), a lower DHA level in adipose tissue is likely due to a lower habitual intake, and is not likely to have been caused by the current depressive state. A case-control study in China has looked for the association of suicide attempt with the levels of EPA and DHA in plasma phospholipids, in patients admitted to emergency services of hospitals either for suicide attempt or for traffic accidents [24]. Sub- 


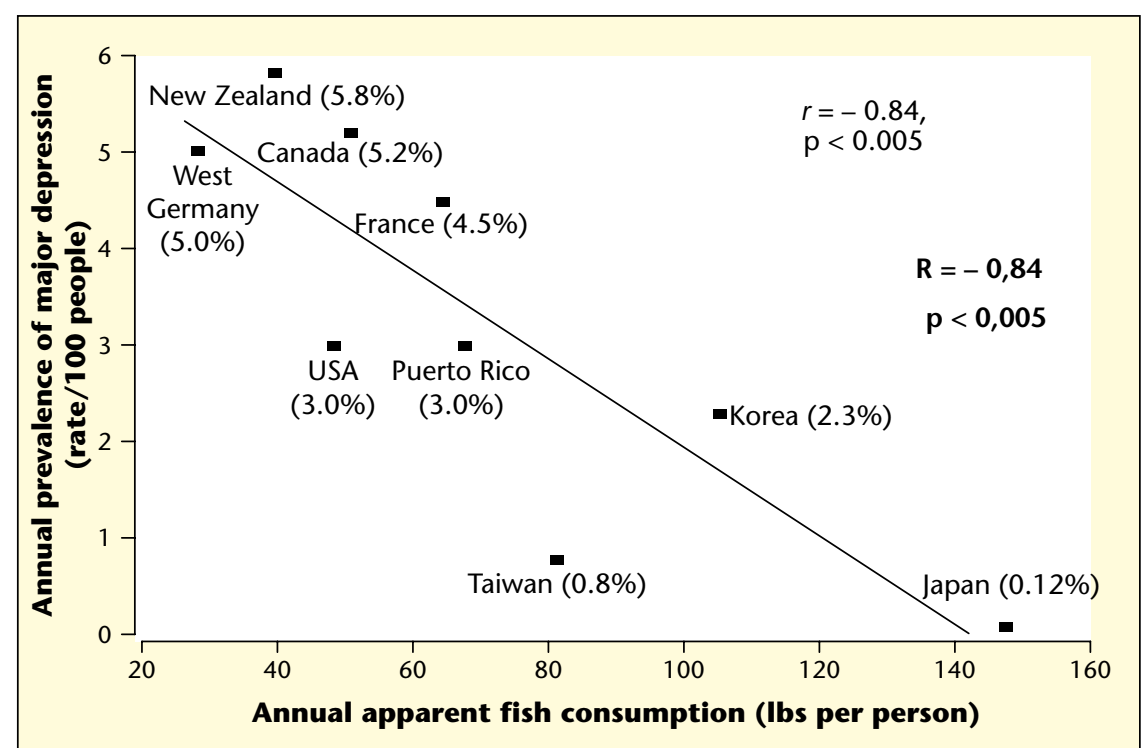

Figure 3. Prevalence of major depression decreases with apparent fish consumption in nine countries (from Hibbeln, [14]).

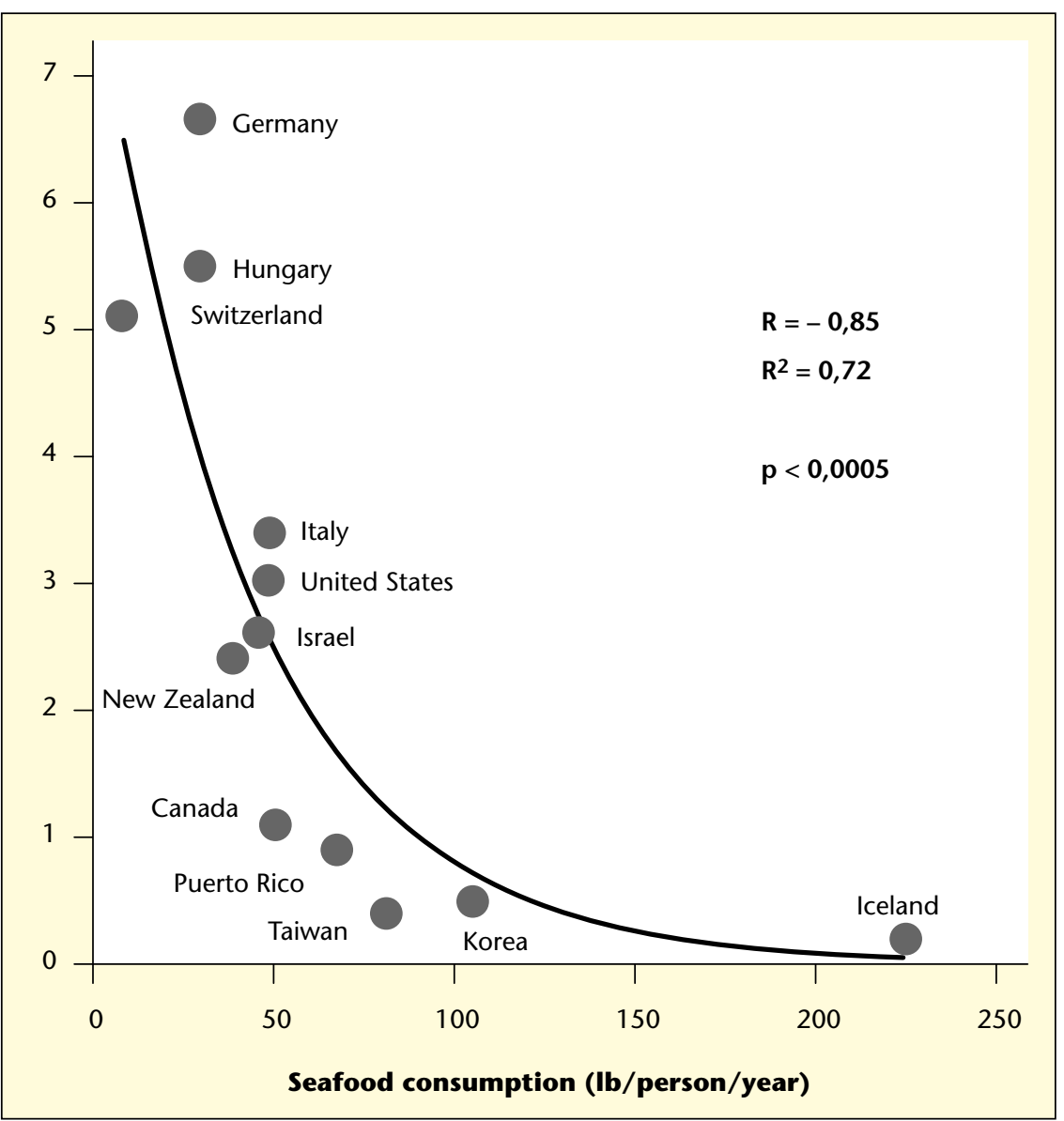

Figure 4. Apparent fish and seafood consumption and prevalence of bipolar spectrum disorders (\%) in 12 countries (from Noaghiul et al., [16]). jects in the highest quartile of EPA or DHA had a very strongly reduced risk of suicide attempt than subjects in the first quartile $(O R=0.12$ [0.04-0.36] for EPA, 0.21 [0.07-0.60] for DHA) [24], suggesting that a low intake of these $n-3$ PUFA can be a very significant risk factor for suicide attempt. Very few studies having searched the association between fish or $n-3$ PUFA intake or status with depression had a prospective design, i.e. in which the tested causal factor (fish or n-3 PUFA intake or status) was assessed before the endpoint (depression). Women with post-partum depression had decreased DHA levels in the lipids of blood taken at delivery (before the onset of depression) [25], which clearly suggests that a low DHA status at birth is a risk factor for postpartum depression. In the French SU.VI.MAX cohort of adult men and women, we have looked for an association of habitual fish consumption, measured by repeated 24-hour dietary records at the beginning of the 8-year follow-up, with the onset of depression during the follow-up, using antidepressant prescription as a marker of depressive episodes (Astorg et al., unpublished). Subjects consuming fatty fish or more than $0.1 \%$ of their energy as long-chain n-3 PUFA have a decreased risk of any depression $(\mathrm{OR}=0.70[0.53-0.82])$ and of recurrent depression $(\mathrm{OR}=0.64[0.43-0.95])$ during the follow-up. The decrease of risk is more pronounced in men than in women, and is especially marked for very recurrent episodes (three or more). In a small prospective study in USA, blood has been taken up from 31 depressed inpatients, and their suicide attempts have been recorded during two years after discharge [26]. A lower plasma DHA level at baseline was predictive of subsequent suicide attempt: $\mathrm{OR}=3.45, \mathrm{p}=0.002$ (below vs. above the median DHA value) (figure 5). A large national cohort study in Japan had found a protective association of frequent fish consumption with suicide during the 17-year follow-up [27]. However, not all studies led to similar conclusions. In particular, in a large cohort study in Finnish male smokers, the ATBC study, no association was found between fish or $n-3$ PUFA consumption measured at baseline and the risk of depression during the 5 to 8-year follow-up [28]. In that cohort, however, a higher intake of omega- 3 fatty acids from fish had been previously associated with a higher risk of cardiac mortality, a result opposite to most other studies [29], which suggests an abnormal response of this population to $n-3$ PUFA intake, perhaps due to interaction with smoking. In summary, many, but not all, observational studies in populations have shown an association between a low fish intake or a low intake or status of long-chain n-3 PUFA and an increased depression risk. The association 


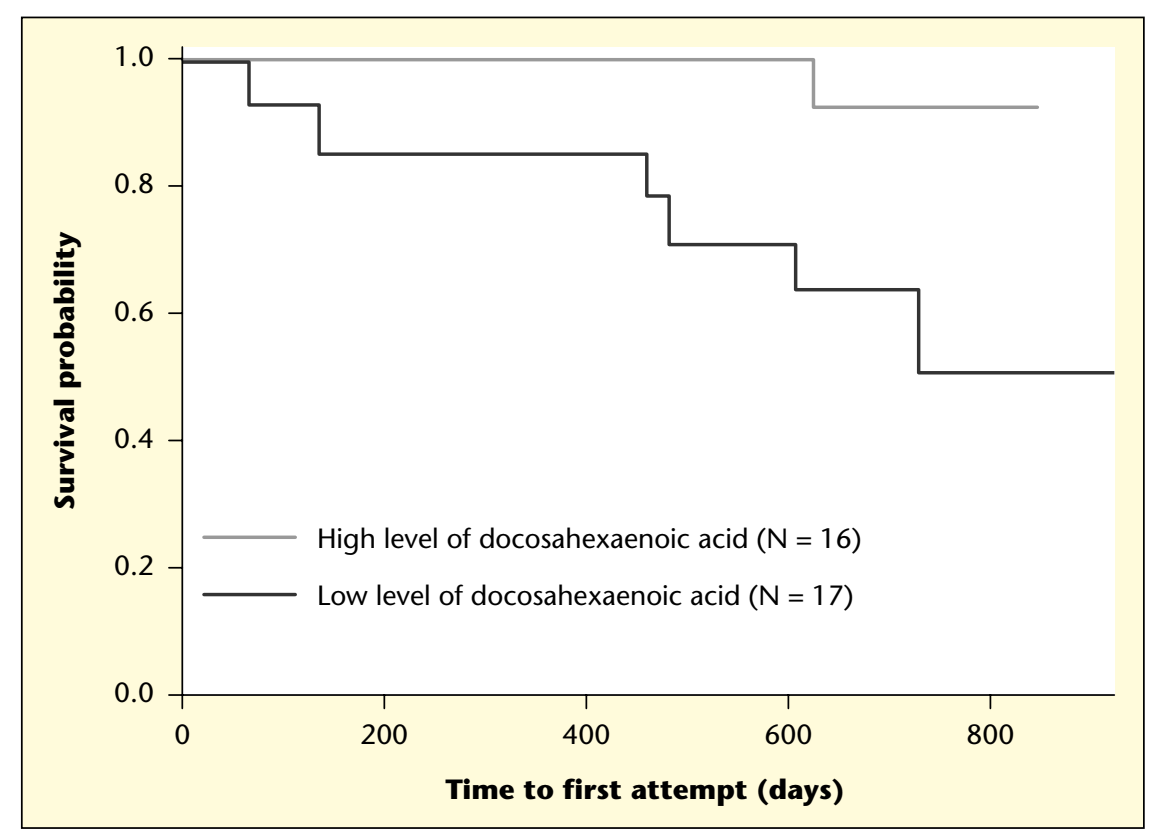

Figure 5. Suicide attempt and n-3 PUFA in erythrocytes: a prospective study in New York (from Sublette et al., [26]).

appeared stronger with recurrent depression and with suicide attempt and suicide. This association has been found in a few studies having a prospective design, which suggests the existence of a causal link between a low intake or status of n-3 PUFA and an increased risk of subsequent depression [25-27] (Astorg, unpublished).

\section{n-3 PUFA and mood disorders: clinical trials}

As soon as 1981, uncontrolled clinical trials on isolated cases of unipolar depression or bipolar disorder have reported antidepressant effects of large doses of linseed oil (containing about $50 \%$ of $\alpha$-linolenic acid) [30]. In the last ten years, randomised, placebo-controlled trials, most of them of small size, have tested the effects of long-chain n-3 PUFA supplementation in patients with mood disorders, either unipolar or bipolar, with ongoing treatment in most cases, but sometimes untreated. EthylEPA or EPA-rich fish oil led to short-term improvement of unipolar depressive patients, resistant to ongoing treatment [31-33]. Curiously, one of these trials having tested several doses of ethyl-EPA found an effect for the lower dose (1 $\mathrm{g} /$ day), but not for higher doses ( 2 and $4 \mathrm{~g} /$ day) [32]. A recent trial on depressed children without antidepressant treatment has shown a remarkable improvement of depressive symptoms in children receiving a moderate dose of $n-3$ PUFA: $0.4 \mathrm{~g}$ EPA $+0.2 \mathrm{~g}$ $\mathrm{DHA} /$ day [34]. Children receiving EPA/DHA had a $50 \%$ decrease of their depressive symptoms score after 12 weeks, whereas those in the Nemets et al. [34]). moderate doses ( 1 or $2 \mathrm{~g} /$ day) [38] or a high dose of fish oil (6.2 g EPA + $3.4 \mathrm{~g}$ DHA/day) [39]. In the latter study, fish oil was active to prevent depressive relapses in both untreated and treated bipolar patients (figure 7). EthylEPA ( $1 \mathrm{~g} /$ day) also improved both depressive and aggressive symptoms in untreated women with borderline personality disorder [40]. However ethyl-EPA at a high dose $(6 \mathrm{~g} /$ day $)$ was not active in depressed bipolar patients [41], and fish oil (4.4 g EPA + $2.4 \mathrm{~g} \mathrm{DHA} /$ day) had no effect on bipolar patients in acute manic phase [42]. The results of these studies are heterogenous, mainly because of the diversity of the patients' diagnoses and of the supplements used (nature and doses). However, some provisional remarks can be made: 1) long-chain n-3 PUFA can be active against depression, in both unipolar and bipolar patients, but not against mania in bipolar patients in manic phase; 2) the supplements found to be active were EPA or EPA-containing mixtures (EPA/DHA 2/1); DHA alone or as a main component of a mixture has shown no effect until now; 3) pure EPA (ethyl-EPA) has shown effects at moderate doses (1-2 g/day), but not at higher doses (4-6 $\mathrm{g} /$ day), however the mixture EPA/DHA 2/1 showed antidepressant effects both at moderate doses $(0.6 \mathrm{~g} /$ day in children) and at high doses (6-10 g/day in adults). Other placebo-controlled trials are necessary to confirm and extent these results, in the aim of knowing the cases where omega-3 long-chain PUFA could be useful in the treatment or in the prevention of mood disorders. Because of their harmlessness and quasi-absence of side-effects,

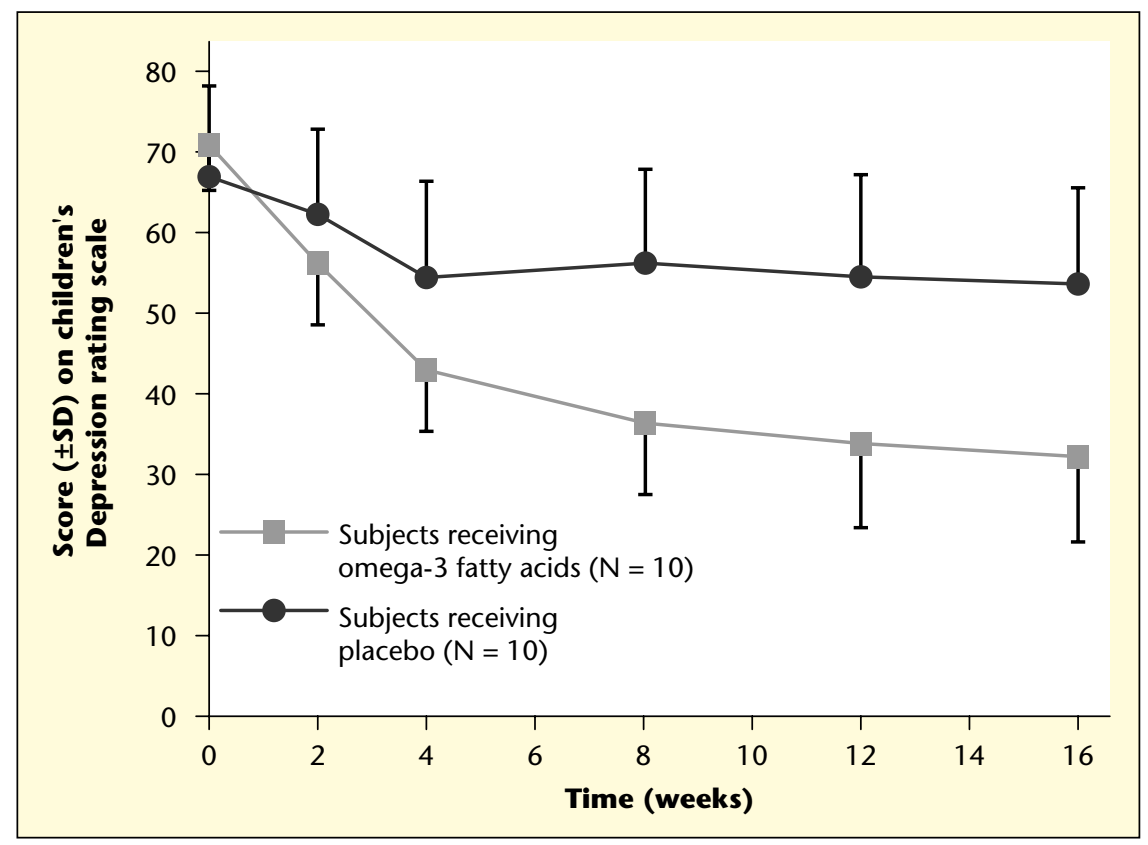

Figure 6. Effect of $n-3$ PUFA as monotherapy (400 mg EPA $+200 \mathrm{mg}$ DHA/day) in depressive children (6-12 y) (from 


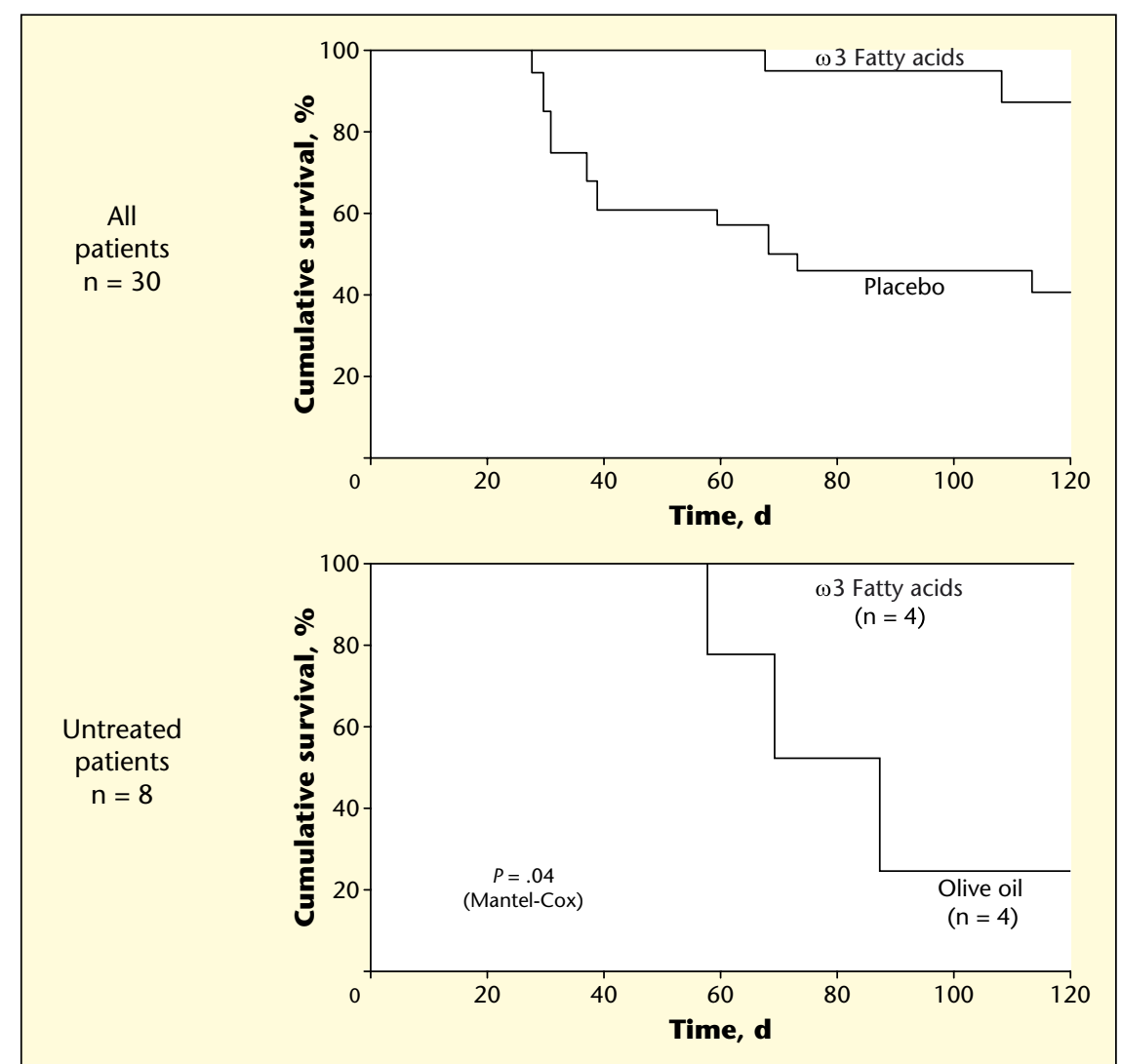

Figure 7. Effect of fish oil ( $10 \mathrm{~g} / \mathrm{d} E P A+D H A)$ given for 120 days to bipolar patients : survival analysis (\% of patients remaining free of depressive relapse) (from Stoll et al., [39]).

omega-3 PUFA appear to be of first interest in cases where a standard antidepressant treatment is not indicated or not desired by the patient: minor depression, depression in pregnancy or post-partum, depression in children. As depression is a very recurrent disorder, and since fish or omega-3 PUFA consumption have been found to be associated with a lower risk of recurrent depression in observational studies [19] (Astorg, unpublished), it would be would be worth to test the effect of long-chain omega-3 PUFA, especially of EPA, as a maintenance treatment in at-risk subjects, i.e. those having experienced a first depressive episode. Such a prophylaxy, if proven to be efficient, could be followed lifetime without any sideeffects.

\section{Conclusions}

On the whole, the involvement of n-3 PUFA, and especially of long-chain n-3 PUFA, in depression and mood disorders is now abundantly documented, in both clinical and population settings, and there is evidence in favor of both a preventive and a therapeutic potency of n-3 PUFA against mood disorders, especially depression. However, many research works are axy, either in the general population or in at-risk subjects; 2 ) in the treatment of patients where a standard antidepressant treatment is not indicated or not desired: mild depression, depression in pregnancy or in children; 3) as adjunct treatment. Last, although some mechanistic studies have been performed in animals [43-45], further research is awaited to explore the mechanisms by which n-3 PUFA can act on mood disorders or prevent them.

\section{REFERENCES}

1. LEPINE IP, GASQUET I, KOVESS V, et al. Prevalence and comorbidity of psychiatric disorders in the French general population. Encephale 2005; 31: 182-94

2. USTUN TB, AYUSO-MATEOS JL, CHATTERII S, MATHERS C, MURRAY Cl. Global burden of depressive disorders in the year 2000. Br / Psychiatry 2004; 184: 386-92.

3. CUIJPERS P, SMIT F. Excess mortality in depression: a meta-analysis of community studies. J Affect Disord 2002; 72: 227-36.

4. KESSING LV, NILSSON FM. Increased risk of developing dementia in patients with major affective disorders compared to patients with other medical illnesses. J Affect Disord 2003; 73: 261-9.

5. ADAMS PB, LAWSON S, SANIGORSKI A, SINCLAIR AJ. Arachidonic acid to eicosapentaenoic acid ratio in blood correlates positively with clinical symptoms of depression. Lipids 1996; 31(Suppl): S157-S161.

6. EDWARDS R, PEET M, SHAY J, HORROBIN D. Omega-3 polyunsaturated fatty acid levels in the diet and in red blood cell membranes of depressed patients. / Affect Disord 1998; 48: 149-55.

7. FRASURE-SMITH N, LESPÉRANCE F, JULIEN P. Major depression is associated with lower omega-3 fatty acid levels in patients with recent acute coronary syndromes. Biol Psychiatry, 2004.

8. MAES M, SMITH R, CHRISTOPHE A, COSYNS P, DESNYDER R, MELTZER H. Fatty acid composition in major depression: decreased omega 3 fractions in cholesteryl esters and increased C20: 4 omega 6/C20: 5 omega 3 ratio in cholesteryl esters and phospholipids. I Affect Disord 1996; 38: 35-46.

9. MAES M, CHRISTOPHE A, DELANGHE I, ALTAMURA C, NEELS H, MELTZER HY. Lowered omega3 polyunsaturated fatty acids in serum phospholipids and cholesteryl esters of depressed patients. Psychiatry Res 1999; 85: 275-91.

10. PEETM, MURPHY B, SHAY J, HORROBIN D. Depletion of omega-3 fatty acid levels in red blood cell membranes of depressive patients. Biol Psychiatry 1998; 43: 315-9. 
11. MCNAMARA RK, HAHN CG, JANDACEK R, et al. Selective Deficits in the Omega-3 Fatty Acid Docosahexaenoic Acid in the Postmortem Orbitofrontal Cortex of Patients with Major Depressive Disorder. Biol Psychiatry, 2006.

12. BILICI M, EFE H, KOROGLU MA, UYDU HA, BEKAROGLU M, DEGER O. Antioxidative enzyme activities and lipid peroxidation in major depression: alterations by antidepressant treatments. J Affect Disord 2001; 64: 43-51.

13. MAES M, DE VOS N, PIOLIR, et al. Lower serum vitamin $E$ concentrations in major depression. Another marker of lowered antioxidant defenses in that illness. I Affect Disord 2000; 58: 241-6.

14. HIBBELN JR. Fish consumption and major depression. Lancet 1998; 351: 1213.

15. HIBBELN JR. Seafood consumption, the DHA content of mothers' milk and prevalence rates of postpartum depression: a cross-national, ecological analysis. I Affect Disord 2002; 69: 15-29.

16. NOAGHIULS, HIBBELN JR. Cross-national comparisons of seafood consumption and rates of bipolar disorders. Am J Psychiatry 2003; 160 : 2222-7.

17. TANSKANEN A, HIBBELN JR, HINTIKKA J, HAATAINEN K, HONKALAMPI K, VIINAMA$\mathrm{KI} \mathrm{H}$. Fish consumption, depression, and suicidality in a general population. Arch Gen Psychiatry 2001; 58: 512-3.

18. TANSKANEN A, HIBBELN JR, TUOMILEHTO ], et al. Fish consumption and depressive symptoms in the general population in Finland. Psychiatr Serv 2001; 52: 529-31.

19. TIMONEN M, HORROBIN D, JOKELAINEN ], LAITINEN J, HERVA A, RÄSÄNEN P. Fish consumption and depression: the Northern Finland 1966 birth cohort study. I Affect Disord 2004.

20. BARBERGER-GATEAU P, JUTAND MA, LETENNEUR L, LARRIEU S, TAVERNIER B, BERR C. Correlates of regular fish consumption in French elderly community dwellers: data from the Three-City study. Eur / Clin Nutr 2005; 59: 817-25.

21. SILVERS KM, SCOTT KM. Fish consumption and self-reported physical and mental health status. Public Health Nutr 2002; 5: 427-31.

22. MAMALAKIS G, TORNARITIS M, KAFATOSA. Depression and adipose essential polyunsaturated fatty acids. Prostaglandins Leukot Essent Fatty Acids 2002; 67: 311-8.
23. TIEMEIER H, VAN TUIJL HR, HOFMAN A, KILIAAN A], BRETELER MM. Plasma fatty acid composition and depression are associated in the elderly: the Rotterdam Study. Am / Clin Nutr 2003; 78: 40-6.

24. HUAN M, HAMAZAKI K, SUN Y, et al. Suicide attempt and n-3 fatty acid levels in red blood cells: a case control study in China. Biol Psychiatry 2004; 56: 490-6.

25. DE VRIESE SR, CHRISTOPHE AB, MAES M. LOWered serum n-3 polyunsaturated fatty acid (PUFA) levels predict the occurrence of postpartum depression: further evidence that lowered n-PUFAs are related to major depression. Life Sci 2003; 73: 3181-7.

26. SUBLETTE ME, HIBBELN JR, GALFALVY H, OQUENDO MA, MANN JJ. Omega-3 polyunsaturated essential fatty acid status as a predictor of future suicide risk. Am / Psychiatry 2006; 163: $1100-2$

27. HIRAYAMA T. Life-style and mortality: a large census-based cohort study in Japan. Basel, Switzerland: Karger, 1990.

28. HAKKARAINEN R, PARTONEN T, HAUKKA J, VIRTAMO ], ALBANES D, LONNQVIST J. Is low dietary intake of omega-3 fatty acids associated with depression? Am / Psychiatry 2004; 161: 567-9.

29. PIETINEN P, ASCHERIO A, KORHONEN $P$, et al. Intake of fatty acids and risk of coronary heart disease in a cohort of Finnish men. The AlphaTocopherol, Beta-Carotene Cancer Prevention Study. Am / Epidemiol 1997; 145: 876-87.

30. RUDIN DO. The major psychoses and neuroses as omega-3 essential fatty acid deficiency syndrome: substrate pellagra. Biol Psychiatry 1981; 16: $837-50$

31. NEMETS B, STAHL Z, BELMAKER RH. Addition of omega-3 fatty acid to maintenance medication treatment for recurrent unipolar depressive disorder. Am J Psychiatry 2002; 159: 477-9.

32. PEET M, HORROBIN DF. A dose-ranging study of the effects of ethyl-eicosapentaenoate in patients with ongoing depression despite apparently adequate treatment with standard drugs. Arch Gen Psychiatry 2002; 59: 913-9.

33. SU KP, HUANG SY, CHIU CC, SHEN WW. Omega-3 fatty acids in major depressive disorder. A preliminary double-blind, placebocontrolled trial. Eur Neuropsychopharmacol 2003; 13: 267-71.

34. NEMETS H, NEMETS B, APTER A, BRACHA Z, BELMAKER RH. Omega-3 treatment of childhood depression: a controlled, double-blind pilot study. Am / Psychiatry 2006; 163: 1098 100.
35. MARANGELL LB, MARTINEZ JM, ZBOYAN HA, KERTZ B, KIM HF, PURYEAR LJ. A double-blind, placebo-controlled study of the omega- 3 fatty acid docosahexaenoic acid in the treatment of major depression. Am J Psychiatry 2003; 160: 996-8.

36. SILVERS KM, WOOLLEY CC, HAMILTON FC, WATTS PM, WATSON RA. Randomised double-blind placebo-controlled trial of fish oil in the treatment of depression. Prostaglandins Leukot Essent Fatty Acids 2005; 72: 211-8.

37. LLORENTE AM, JENSEN CL, VOIGT RG, FRALEY JK, BERRETTA MC, HEIRD WC. Effect of maternal docosahexaenoic acid supplementation on postpartum depression and information processing. Am / Obstet Gynecol 2003; 188: 1348-53.

38. FRANGOU S, LEWIS M, MCCRONE P. Efficacy of ethyl-eicosapentaenoic acid in bipolar depression: randomised double-blind placebocontrolled study. Br / Psychiatry 2006; 188: 46-50.

39. STOLL AL, SEVERUS WE, FREEMAN MP, et al. Omega 3 fatty acids in bipolar disorder: a preliminary double-blind, placebo-controlled trial. Arch Gen Psychiatry 1999; 56: 407-12.

40. ZANARINI MC, FRANKENBURG MD. Omega-3 fatty acid treatment of women with borderline personality disorder: a double-blind, placebocontrolled pilot study. Am / Psychiatry 2003; 160: 167-9.

41. KECK JR. PE, Mintz J, McElroy SL, et al. Doubleblind, randomized, placebo-controlled trials of ethyl-eicosapentanoate in the treatment of bipolar depression and rapid cycling bipolar disorder. Biol Psychiatry 2006; 60: 1020-2.

42. CHIU CC, HUANG SY, CHEN CC, SU KP. Omega- 3 fatty acids are more beneficial in the depressive phase than in the manic phase in patients with bipolar I disorder. / Clin Psychiatry 2005; 66: 1613-4.

43. PARKER G, GIBSON NA, BROTCHIE $H$, HERUC G, REES AM, HADZI-PAVLOVIC D. Omega-3 fatty acids and mood disorders. Am J Psychiatry 2006; 163: 969-78.

44. SINCLAIR AI, BEGG D, MATHAI M, WEISINGER RS. Omega 3 fatty acids and the brain: review of studies in depression. Asia Pac / Clin Nutr 2007; 16(Suppl 1): 391-7.

45. SUBLETTE ME, RUSS MI, SMITH GS. Evidence for a role of the arachidonic acid cascade in affective disorders: a review. Bipolar Disord 2004; 6: 95-105. 